\title{
Transforming a school: A case study of a Catholic school principal in Indonesia
}

Oei, Siok Fei $\bowtie$

Graduate Institute of Educational Leadership and Development, Fu Jen Catholic University, Taiwan (oeifei@yahoo.com)

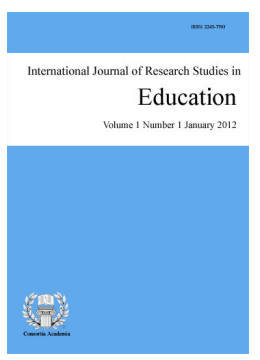

ISSN: $2243-7703$ Online ISSN: 2243-7711

OPEN ACCESS

\section{Abstract}

Transforming a struggling private Catholic Vocational School into a well-improved school requires a lot of hard work. Improving a school allowed for no short-cut to assure students' high achievement. An outstanding school was the result of much hard work. The current case study shall focus on the journey of Mater Amabilis School for Training Home Economics Teachers (MA SGKP). More specifically, the paper shall focus on how a school principal transforms a low-performance school into a high-performance school, while considering the impact, and the perception of the local school community.

Keywords: Catholic school; school principal strategies; transformation; leadership; case study; Indonesia 


\section{Transforming a school: A case study of a Catholic school principal in Indonesia}

\section{Introduction}

Inspired by an educational movie based on a true story Lean on Me, which illustrated how Joe Clark as the school principal led and transformed an inferior school into a high-performance school, and also the research study of Miller (2011) about A Phenomenological Case Study of a Principal Leadership: The Influence of Mr. Clark's Leadership on Students, Teachers and Administrators at Eastside High School, the researcher is directly related to a fellow Catholic Sister who is a school principal with a life experience almost the same as Joe Clark's. She was asked to lead a private Catholic vocational school which was nearly shut down because of a decrease in the number of students. The school had a reputation for low quality, so it became unpopular. For many years the researcher has been noticing the improvement of the school this Sister administers. Filled by curiosity, since 2011 until 2014, while accompanying Fu Jen University students for service-learning at Mater Amabilis Vocational School (MA SMK) where this school principal works, the researcher has attempted to understand the specific reasons for the success of the school principal transforming the school. The researcher tried to collect and analyze the documented data of the school to see the progress of the principal in the transformation of the school.

\subsection{Dying Era}

At the beginning, the journey of Mater Amabilis School for Training Home Economics Teachers (MA SGKP) received a positive response from society so that the number of students who were studying in the school was quite high, and their contribution to society was an awesome achievement which added to the popularity of MA SGKP even beat School for Training Home Economics Teachers (SGKP) State in Surabaya. In 1977 government policy determined that students who graduated from Family Welfare Secondary School (SMKK) could not go on to College unless they received a grade of 75 . This policy was an external factor that continuously impacted on the decreasing number of students at MA SMKK, which in 1996 changed its name to MA SMK. This situation became a heavy burden for Joseph Foundation in its operational funding of the school.

At the lowest point (1998-2003), when the students were only 96 in number it appeared inevitable that MA SMK would be closed. The assumptions underlying internal factors that decreased the number of students were as follows:

$>$ Less promotion

$>\quad$ Less involvement in social activities (exhibitions, competitions, performing arts)

$>\quad$ Less attractive physical appearance of the school and learning facilities

$>$ Inadequate human resources (problems with teachers)

$>\quad$ Lack of effective leadership-management

$>$ Receiving students who were physically and mentally handicapped. Society was less interested in them because in the paradigm of the people at that time the presence of handicapped students was not appropriate at "normal" schools.

\subsection{Resurrection Era}

After a certain careful thought and consideration, a long process of discernment followed in the school year 2004/2005, at which time the Catholic Missionary Sisters Servants of the Holy Spirit (SSpS) Congregation decided that MA SMK should remain in operation and would strive to develop itself. With a new competent Principal (Sr. Y. SSpS) with much experience in managing and organizing a high school and who was a former Provincial in the SSpS Congregation Java Province, MA SMK started its resurrection precisely in November 2004. Specifically it was stated that all components at MA SMK were consistent with the commitment "Willing to work hard for the improvement of our school." 
Transforming a school: A case study of a Catholic school principal in Indonesia

In the course of time it was found that teachers and staff who could not work hard and maintain consistency must be eliminated by the system. Starting with the school year 2004/2005, MA added two new courses, namely: Travel-Tourism Business and Hotel Accommodation/Hospitality. Thus, there were four courses. According to Government Regulation No.19 - year 2005 to meet National Education Standards, Mater Amabilis (MA) Catholic Vocational School was included in the tourism cluster four courses: Food Science/Catering (JB), Fashion Design (BB), Hotel Accommodation/Hospitality (AP) and Travel-Tourism Business (UPW). Vocational education at MA included (and still includes) several components for achieving school improvement: school management, human resources, curriculum, student organization, public relations, and infrastructure.

\subsection{Rising Era}

Within the rising era, the school principal provided new buildings and equipment that are needed for the learning process inside and outside the school. First of all, the principal renovated classrooms for theory and practicum, procured industry standard equipment for expert practice, and cultivated school-based settings for a "green environment" with shaded gardens that drew increased public interest. To accommodate the increasing number of new students, the principal also built larger classrooms. Moreover, the principal provided additional facilities such as installation of CCTV, air conditioners and free Wi-Fi networks, all of which again attracted public interest. In the year 2012, the principal renovated a new building comprising seven classrooms (the quality surpassed Indonesian vocational school standards), and arranged for waste water services by the Zero Waste Water System (ZWWS), for which two years ago (2012) the school received the first place at the national level as a school for promotion of the environment.

Based on school documents, the researcher feels and senses obviously that the school principal has played the most important role in improving and transforming the school. This point of view was in line with the statement of Sergiovanni (1995) who stated in his book The Principalship that "an important key to quality schooling is the leadership that school principals provide directly and promote among teachers and supporting staff" (p. 146). This assertion was also supported by hundreds of studies on school effectiveness and success in high-performance schools (Izumi \& Yan, 2005; Stephens, 2008). These findings pointed to the role of school leadership as a key factor in the success of schools. Research also indicated that the difference between high and low-performance schools was due to the impact of the principal (Stephens, 2008, p. 96). Indeed, these statements were affirmed by the research of Bottoms and Schmidt-Davis (2010) who said that one of the essential elements that had to be in place for struggling schools to improve in substantive ways was principal leadership. Furthermore, the research of the Wallace Foundation stated that "a principal remains the central source of leadership influence" (2013, p. 6).

Taking this point, the motivation of the researcher using a case study is to find specifically the potentials of a particular school principal in improving a school. Initial research questions are as follows:

$>\quad$ What strategies has the school principal used in transforming MA SMK?

$>$ How do these strategies impact on the school community (students, teachers, parents, board of trustees, and administrator)?

$>$ How is the school principal perceived by the school community (students, teachers, parents, board of trustees, and administrator)?

\section{Methodology: Phenomenological Case Study}

According to Yin (2003), investigating a multilevel social phenomenon by using a case study methodology was the right choice for the integration of many methods to explore a contemporary situation. In this case, Stake (1995) firmly recommended that case studies could contribute both theoretically and pragmatically to education research because of their holistic approach to educational environments as complex social affairs. Therefore, the 
researcher chose to make use of a descriptive phenomenological case study methodology in investigating school principal strategies at MA SMK with a lens to view the impact and perceptions of the principal, and the school community (students, teachers, parents, alumna, a board of trustee, and an administrator). Merriam (1998) affirmed that a qualitative method was an essential way to undertake and evaluate educational research because the data collections consist of participants' interviews and observations from the research. Above all, once again Merriam declared that case studies could be categorized as descriptive, interpretive, or evaluative. Thus, a case study might be the most suitable method to compose a study that included multiple qualitative sources in its investigation (as cited in Miller, 2011, p. 59).

Patton (2002) stated that by conducting a case study, the researcher had the advantage of observing the phenomenon under study within the natural setting in which the phenomenon occurred. This in-depth process had resulted in research with a great deal of depth, paying careful attention to detail, context and nuances which were present in the school setting. Furthermore, Merriam (1998) said that the subject of a case study could be an entity, namely an object, program, person, organization, or phenomenon. Therefore, the researcher investigated the phenomenon of Sister Y as a principal of MA Vocational School as the case under study, engaging the perceptions of individuals who were students, a former student, parents, teachers, a board of trustee, and an administrator over a period of a nine-year tenure.

\subsection{Participants}

In a phenomenological case study, Creswell (2007) asserted that the participants:

$>\quad$ "Had to be individuals who have experienced the phenomenon being explored...

$>\quad$ Were able to articulate their conscious experiences...

$>\quad$ Were able to provide important contextual information useful in the axial coding phase of research...

D Participated in a process that was central to the research" (pp. 111-114).

Based on these criteria, purposive sampling was used in selecting the participants. Additionally, in order to get more informants, the recruitment of the participants used chain sample. After getting permission by verbal approval of the school principal to conduct research related to her strategies transforming MA SMK into a high-performance school, the researcher contacted and asked the chairwoman of the Board of Trustees at MA SMK for suggestions for sources of information about the phenomenon under study. Then she gave the name list of the teachers and staff members who had close connections and much experience either with the principal or the transformation process of the school itself as well.

Afterwards, the researcher approached these persons in person and purposefully selected those who met criteria. Four teachers, one administrator, the school principal $(\mathrm{Y})$ and the former chairwoman of the Board of Trustees enthusiastically participated in this study. To get more integral information as one school community, the teachers suggested interviewing two students, an alumna and two parents who also met those criteria. Fortunately, they were ready and available to be interviewed. In this way, the researcher gained twelve participants for this study by taking into account that they could present rich data in their perceptions about the phenomenon under study and be especially able to articulate their conscious experiences. The twelve participants are:

$>$ The school principal (Y) herself as the primary person of this study.

Two students who are chair and vice chair of the student council interacting directly with the principal.

$>$ An alumna who regularly keeps contact, visits, asks advice and relates closely with Sister Y.

$>$ Four teachers who are now assistant principals in different programs have known Sister Y well for 
Transforming a school: A case study of a Catholic school principal in Indonesia

many years, and thus, have a lot of experience in pain and joy with her, and have participated in the transformation process of school.

$>\quad$ An administrator who is working with Sister Y as her current secretary.

$>\quad$ Two parents who have known Sister Y well because their children graduated from MA SMK, and they still keep contact with her.

$>\quad$ The former Chair of the Board of Trustees who has participated in the transformation process of the school and has known Sister Y well for many years.

\subsection{Data Collection}

The interview for collecting data was designed in two parts. The first part was for the principal, and contained a 14-question qualitative interview protocol. The second part was for the school community, and contained a 9-question qualitative interview protocol. The interview took place in a private area of MA SMK. The primary data of this phenomenological case study were qualitative data collection which the researcher gathered via direct visits to MA SMK to obtain school documents, one-hour individual interviews with teachers, administrator, students, alumna, parents, a former chair of the board of trustees, and the principal. Moreover, the visits provided various benefits, namely, the researcher receiving an opportunity to observe the whole school and to conduct one on one in-depth interview with each participant by using a digital voice recorder, useful for transcriptions and storing accurate information. To protect the participants, real names were not be used in the recordings, transcriptions, or the final research study. The information that the participants shared was kept private and confidential.

In the end, qualitative data triangulation was used to cross-check the interview data by observing the principal's behavior in a natural setting and to conduct document analysis. Also, the researcher used Skype and email to search for further information or to confirm details (member checks). Patton (2002) described interviews, observations, and document analysis as appropriate forms of qualitative data, and further explained that they were needed for qualitative data triangulation, which strengthened the validity and reliability of findings.

\subsection{Qualitative Data Coding}

Miles and Huberman (1994) noted:

Codes are tags or labels for assigning units of meaning to the descriptive or inferential information compiled during a study. Codes are usually attached to 'chunks' of varying size words, phrases, sentences or whole paragraphs (p. 56).

Conducting a qualitative phenomenological case study, the researcher did coding to organize the raw data into conceptual categories. The procedure of doing this coding was as follows:

$>\quad$ The interview and document data were carefully read, all statements relating to the research question were identified, and each was allocated a code or category.

$>$ After noting the codes, the researcher organized them into relevant statements.

$>$ Afterwards, the researcher reread the data and searched for key words which fit into a variety of categories.

$>\quad$ Then the researcher reviewed the codes and made critical analysis.

$>\quad$ Through critical analysis, the researcher searched objectively what was contradictory, and what was confirmatory data.

$>\quad$ To avoid confirmation bias, the researcher was not selective in choosing data, but searched as objectively as possible.

$>\quad$ The researcher then clustered the data units (key words, sentences, statements, etc) into groups with different meanings. 
$>$ Lastly, the researcher reviewed and critically reflected on her own role within the whole data collection process as a sign of awareness.

\subsection{Data Analysis}

Before entering the process of data analysis, first, the researcher started the step of getting to know the data by listening to the digital voice recorder, transcribing the interviews from the recorder to paper, and reading over the written transcripts. After doing this, the researcher had common ideas of what the participants were saying. Starting the process of data analysis, surprisingly, the researcher found that the more rigorous the analysis, the more integrated the information obtained. Scientifically, Guion, Diehl, and McDonald (2011) asserted that in order to increase the validity of a study, researchers should collect data triangulation by using different sources of information to obtain more integrated information. For this study, the sources were the school community (teachers, an administrator, students, alumna, parents, a former chair of the board of trustees and the principal). In-depth interviews were conducted with each participant to gain more insight into their perspectives on the phenomenon under study. Interviews, observations, and document reviews were the multiple sources used to gather data. By using this combination, the researcher was able to validate the data through triangulation and cross reference (Merriam, 1998; Yin, 2003).

During the analysis stage, feedback from the school community was compared to determine areas of agreement as well as areas of divergence and additional observational data were needed to better inform the field on how the principal implemented the strategies. Careful observation led to a sharper sense of school climate and culture. Firmly, Thurmond (2001) declared that the benefits of triangulation were "increasing confidence in research data, creating innovative ways of understanding a phenomenon, revealing unique findings, challenging or integrating theories, and providing a clearer understanding of the problem" (p. 254). These benefits mainly result from the variety and amount of data that can be used for analysis (Guion et al., 2011).

After collecting the data transcription and data triangulation, the researcher analyzed the data, searching for "significant statements, sentences, or quotes that would provide an understanding of how the participants experienced the phenomenon" (Creswell, 2007, p. 25). Shortly thereafter, the researcher conducted face-to-face or Skype interactions with participants to share analysis results with them as a means of member checking. At this time, the researcher asked their opinions of the findings to allow for more investigation new information or knowledge. The researcher was curious to find whether the results appeared to be conscientious reflections of what participants meant to express or not.

Next, specific themes were identified by "clustering" the invariant constituents. Clustering is a process in which respective theme meanings naturally combine themselves. The question is whether "there seems to be some common theme or essences that unite several discrete units of relevant meaning" (Hycner, 1985, p. 287). As a form of validation in this process, Moustakas and also Hycner (as cited in Miller, 2011, pp. 70-71) said that the relevant expressions were checked by asking two additional questions: (1) are the expressions clearly articulated in the complete transcript? (2) are the expressions coherent and clearly communicated? If the expressions were not fit or clear, they were eliminated. In Glaser and Strauss' study (as cited in DeVault, 2011, p. 1) this step of data analysis was attained by wallowing in the data.

\section{Strategies that the School Principal used in Transforming MA SMK}

Private vocational school transformation movements have much to learn from the strategies of school principal (Sr. Y) at Mater Amabilis Catholic Vocational School (MA SMK). The school employs 50 full-time teachers and enrolls approximately 600 students. Courageously and steadily, the school has taken great steps and made progress in improving itself, as is evident in student achievement during the last nine years. Currently, as evidence of MA's success, the Department of Education has accredited its performance with a grade 94, 5 (A = excellent). MA SMK has obtained operating licenses extending to 2018. To improve its governance MA SMK has decided to use Quality Management System (QMS) ISO 9001: 2008 from 2010 till now. 
Transforming a school: A case study of a Catholic school principal in Indonesia

In an effort to trace the progress of principal (Sr. Y) in improving the school through her strategies and role, the researcher catalogued and investigated data by consideration of the nine characteristics of schools' high performance, found by Shannon and Bylsma (2007). After thorough analysis of the document data of MA SMK, the transcriptions of the interviews with the principal, and participants, the researcher discovered and organized 13 strategies the principal used for transforming MA SMK into a high-performance school. Nine strategies she used had characteristics which were similar to the findings of Shannon and Bylsma (2007)'s nine characteristics of high-performance schools: (1) clear and shared focus, (2) expectations of all students to meet high standards, (3) effective Leadership, (4) collaboration and communication, (5) curriculum, instruction and assessment beyond standards, (6) development of learning and teaching, (7) fostering of professional development, (8) support for learning condition, (9) family and community involvement. But surprisingly, the researcher found four more strategies (Sr. Y) used for transforming MA SMK, namely: (10) shaping school culture, (11) using SWOT analysis, (12) product marketing, and (13) school promotion.

\subsection{Clear and Shared Focus (Vision-Mission-Goal-Direction)}

Earlier sense of mission was concerned with forming a people of faith who grow in innovation, creativity and professionalism, and yet care about life-giving relationships for the small, the weak and the poor of society. The past mission valued: (1) fighting for the life and the development of MA vocational school and utilizing the potential and creativity of the school community as well as individual members; (2) running and developing effective programs rooted in the moral value of education. Past goals included: (1) to help, guide, and educate students in building their futures as professional, reliable, skillful and mature persons through their education at MA SMK; (2) provide adequate welfare benefits to teachers and staff members who are able to perform tasks well; (3) encourage teachers and staff to develop skills and professionalism. Unfortunately, this vision-mission-goal was neither clear nor a shared focus on the implementation of school programs. The first thing the principal (Sr. Y) did for to transform MA SMK was to establish the direction and formulate the vision-mission-goal of the school.

According to Sr. Y, at the inauguration of the principal of MA SMK, the first question she asked at the teachers and staff was: "do you want to live or die?" and they shouted "we want to live!" so she responded "if you want to live, you have to work hard. Are you willing and ready to do it?" enthusiastically they all shouted "we are willing and ready!" Based on their answer, the first day entering MA SMK, she engaged herself with all the teachers and staff to confirm the direction and formulate the vision-mission-goal of the school. Starting with the right question, she touched the hearts of teachers and staff. She had the ability to articulate a compelling vision based on the core values of the school. She knew where to go and described the direction in a clear and compelling way. Some evidence is available from teachers' statements during the interview.

$\mathrm{V}$ said, "Our vision-mission statement was a direction to form our mind-set to focus on nurturing love, SSpS spirituality, and a commitment to live in service for teachers and students. In meetings, our principal always reminds us about the values that animate our vision. In my observation, 90\% vision-mission-values were implemented in the hearts of teachers - staff so we have sense of belonging to the school and students. She also asks us to embrace all students - with no discrimination because our duty as teachers is to transform all students into skillful/capable students in work." (V-1)

$\mathrm{M}$ also stated: ..... Improving our vocational school, she gave a clear direction and provided a work world for students. (M-1)

Y explained: ...... Each unit was made in accordance with the vision-mission program that has been agreed upon. (Y-1)

Based on document data and direct observation, at the wall of the school, facing the school garden, these words appear: the directions and objectives of Mater Amabilis Catholic Vocational School (MA SMK) are contained in 
the vision and mission statement. The new vision statement: forming people of faith, who are mature in knowledge, creativity, innovation, social-mindedness, entrepreneurship, culture and environment.

The new mission has as its goals: (1) helping students to integrate Christian value with the development of their personalities; (2) training students to be reliable, professional and serve for others; (3) fostering students' internal attitude: DICIUM (Discipline - Deft - Initiative - Tenacious - Militant); (4) nurturing students' external attitude: KISS (Coordination-Integration-Sympathy-Simplicity); (5) helping students to develop an entrepreneurial spirit; (6) to create an atmosphere of true brother-sisterhood; (7) to implement sustainable environmental education. To influence the hearts of all persons in the school community, the principal engraved a motto of MA at the top of the main gate and at the wall of school along the corridor. The motto was "Excellence in Quality, Courtesy in Action" is a way of life to reach the GATE OF SUCCESS.

To objectify the Vision-Mission-Goal of MA SMK, the principal concretized a clear and shared focus characteristic of a work program: (a) a long-term program (5 years) called RIPS (School Development Master Plan); (b) a medium-term program (3 years) called Renstra (Strategic Plan); (c) a short-term program (1 year) called Progta (Annual Program).

\subsection{Expecting All Students to Achieve High Standards}

During the dying era, the school outcomes and the quality of education were average and the students were not offered an ambitious and rigorous course of study and did not compete in contests to measure their skills or productivity. Without reinforcement and affirmation for their skills in competition, without enthusiastically promoting the results of their work, the students studied without high spirits, unenthusiastically. In highly effective schools there is a sense that all have a responsibility to educate students, not just teachers and school staff. Led by Sr. Y as the principal, the students had many opportunities to measure their skills and productivity in many competitions and contests. When asked about which strategy had the biggest impact on developing MA SMK, two teachers stated:

E's comments: .... The principal had high expectations for the success of students. Student achievement was our priority. Students got more opportunities to compete in contests as a means to be increasingly known to the public. To improve students' skills, Sister provided on-the-job-training (catering, bakery, travel and tour guide, garment business, hotel hospitality). $(\mathrm{E}-1)$

M's comments: ... expecting all students to achieve at a high standard was our priority. We emphasized real-work training for them. Now we are providing a lot of skill training, selling and promoting the products of students' work, networking with industries and factories so the students are recognized more than undergraduate students.... Improving a vocational school, she gives a clear direction in providing a work world for the students. Her motherly approach to the students makes the students feel at home and the school becomes their second home. (M-2)

Indeed, Sr. Y demands performance standards with high expectations. The academic goals of the school and high quality achievement, confidence that students will meet the demands of courses and performance standards, requires knowledge and skills for the workplace. Teacher expectations are conveyed through actions: collaborative actions in common lessons, assessments, looking at student work with effective questioning strategies of teaching, minds-on student engagement through practical productivity. To understand what the principal has done for the growth of students' skills and talents, we can observe data related to school achievement and the comments of parents, students and alumna in interviews.

Vn's comments: .... My daughter was able to sharpen her talents and skills. She felt this school gave her space to practice her talents and skills. I am grateful to see the growth of my daughter since she began to study here. She told me that the principal was full of support, care, and warm 
Transforming a school: A case study of a Catholic school principal in Indonesia

greetings for the students. Also the teachers gave her support. Now she is more mature, and able to prioritize which needs are more important. (Vn-1)

O and D's comments: .... Our bakery products are well-known in Surabaya. Every year the number of students increases greatly. Our progress in learning: is due to our study of 4 foreign languages, productivity and sharing. Our school regulation was disciplined and on time, so students had to make efforts...... Moreover, MA SMK provides basic exercise leadership and mental - spiritual faith formation for the integrated growth of students (e.g. rehearsals, spiritual events, military training and live-in sessions). Principal Y gives loving concern to the students, invites us to be more inclusive, disciplined, detailed in job-description - a clear objective, and teamwork. We also rely on monitoring and direct interventions, and give some solutions to choose the better way. (O-D-1)

The data of school achievement and the statements of teachers, parents and students prove to the researcher that the principal (Sr. Y) has succeeded in sharpening the students' skills and their product quality even as Sr. Y has transformed the students' quality of life to be more mature in dealing with difficulties and challenges.

\subsection{Effective Leadership-Management}

Shannon and Bylsma (2007) said that in order to develop a school, the leadership of a principal should be effective in carrying out the process of transformation and should also be proactive in seeking assistance. Unfortunately, when MA vocational school was in a dying condition, from the document data, there was a note written an assumption underlying internal factors that decreased the number of students: less effort to renew effective school leadership. This was also confirmed by the testimony of E, who said: .... Before principal Y, our school leadership was much more one-way instructional leadership, and lacked synergy and teamwork. (E-2)
EP said: .... At that time our failures were
(Internal) we were lacked teamwork, innovation
and creativity because our school leadership was not yet effective and our graduated students were not accepted in industry and society yet. (EP-1)

In order to motivate others to attain school goals, effective principal leadership should grasp and embrace the whole staff and teachers, and involve them in the school goal formulation process. By together committing themselves to and carrying out the school goals, trust, reliability, a spirit of community and active participation within the school result. School principals who ask their teachers to engage in truthful and open dialogue and who also value and heartily welcome teachers' proposals and suggestions get more trust from the teachers and staff. Furthermore, teachers and staff were then ready to follow the direction the principal set (Lezotte \& McKee, 2006). In this regard, McLaughlin and Talbert (2006) affirmed that school witness robust improvement when principals learnt to trust by giving others space to grow and help them to "participate in building leadership throughout the school" (p. 81).

Through thorough analysis of MA's document data, the researcher found what the principal did to lead the school effectively and transform it into a qualified school. The principal cared especially about school management, human resources (HR), the curriculum, student organizations, public relations, and infrastructure. To explain further:

V said: Our principal developed many areas in MA such as physical plant, the teaching-learning process, green environment, HR, media learning - technology literacy, how to operate LCD, laptop, power-point, and many others; facilities (computer lab, language lab), student centered, financial management system...... (V-3)

W said: Our principal made a big change in our administration office by installing a centralized computer system. All classes had LCD. The school atmosphere also gradually changed a lot with 
Adiwiyata program (environmental education). As a result, we now have a waste water treatment plant (ZWWS), a biopolymer well, a greenhouse by using coconut fiber instead of soil. There we plant medicinal plants for family (abbreviated TOGA) which is a plant cultivated as a nutritious home-based medicine, also other plants such as orchid, rose, greenery plants, etc. (W-1)

The findings from document data analysis of MA SMK relate the strategies the principal (Sr. Y) used for transforming MA SMK into a high-performance school.

\subsection{School Management}

School management was implemented by using the School-Based Management (SBM) system. SBM is a management system that involves the staff of teachers, parents, students, alumni, the wider community, higher education and Junior High School. Broadly speaking, through a thorough analysis of MA's document data, the researcher found the management team of the school describes the application of SBM at MA via 7 components in the school, namely:

A. Teachers Staff: the work form consists of a Management Team of a Principal, Vice Principals, and Heads of the Study Program. The main task of teachers is to teach and educate the students, whereas the management team, in addition to carrying out main tasks, is also actively involved in developing the school.

B. Parents: parents' role is as a source of funding and opinions and suggestions on the development of the school through the school committee at the time of preparing programs at the beginning of the school year and evaluation activities at the end of the school year.

C. Students: the main task of students is to gain knowledge for their lives. Another role is to support the school community through school promotion activities such as exhibits and participation in competitions held by the Department of Education and Society.

D. Alumni: the role of alumni is a significant and powerful role because alumni witness to the work and success of the school which society expects. Indirectly, the success of alumni in a work place and in general society is a magnetic attraction for people to study at MA SMK.

E. Community: the wider community means the Department of Education, industry world, universities and junior high school. The Department of Education serves as a protective institution, developer of educational resources, sources of funding, coaching and assessment. Industry World is the major goal of graduating students to work according to their expertise, but is also a place to practice skills for students and teachers as well as resources for the tourism industry. In addition, besides the school has established good relationships with several families who are able to be benefactors for students who are less fortunate.

F. Higher Education: an alternative destination for students to deepen their expertise, as well as resources, and become working partners in developing human resources.

G. Junior High School: an input source (prospective students/candidates) who will continue to study for 3 years (6 semesters). In the midst of increasingly tough competition, the management team must be able to establish positive relationships with junior high schools in order to be allowed to promote MA SMK directly, or invite students to participate in special promotion programs.

To further exemplify the application of SBM at MA SMK via the 7 components discussed above, the principal (Sr. Y) herself stated:

To transform this school, first of all I used a participative leadership model because I need all the MA community to participate in synergy. A Principal should be in collaboration with the Vice 
Principals (dealing with curriculum, students, public relations, marketing, on-the-job-training), government (Ministry of Education on city and province level). Moreover the principal also works with department program heads: Catering Program, Program in Hospitality Accommodations, Service Business Travel-Tourism Program and Fashion Design Program. We have routine meetings to coordinate changes or new programs. Sharing, confirmation and clarification are always open for the progress of our school. We also accommodate and respond to each person's aspirations. I believe in everyone in our school community, respect and ensure their welfare. For example, the earnings canteen and production unit are divided into three: for operational, for poor students and for the welfare of teachers. Participative leadership strategy is our method. It means the involvement of all teachers, staff and parents of students is needed in accordance with their respective roles. I think the transformation was the result of participative leadership. (Y-2)

\subsection{Human Resources (HR)}

Human Resources are the most important component in a work plan, in implementing, evaluating and analyzing it to reach goals with maximal results. And the most difficult thing is to get human resources that are competent in their field and willing to strive for developing the school without calculating how much benefit that will receive.

M stated: .... Before principal Y's leadership, the atmosphere of MA was so rigid and death-like, with weak Human Resources (sleeping HR), not smart in looking for opportunities.... (M-3)

An assessment of performance by teachers and employees, and recommendations for improved quality of education occurs at the end of the school year. To develop human resources, the principal provides seminars, workshops, educational trainings, and project rehearsals, comparative and advanced studies. In this case, some quotations from teachers are useful:

V said: What I appreciate most is she gives us a chance to study further and delegates us to attend important meetings so we can learn more and be better leaders. She told us, "This school is your fixed income for feeding your families. If the school is shut down, who will suffer? The future of this school is in your hands! I'm not here forever, so you must learn unceasingly to gain more knowledge and skills on how to improve your school." (V-4)

E stated: principal Y gives skill-training, full trust, authority and freedom to all the heads of programs to develop and innovate by using creativity ...... Human resources was demanded to be more qualified minimal bachelors, provided skill-coaching training, advanced study (the fee is $50 \%$ personal, $50 \%$ school). To improve students' skills, she provides on-the-job-training (catering, bakery, travel and tourism, garment business, hotel hospitality). (E-3)

\subsection{Curriculum}

The curriculum is established, manages the whole process of learning in the school, and calls for a change in attitudes, knowledge and skills. On the dying era, MA implemented its vocational curriculum purely from government initiative (not yet developed it into something interesting or innovative and unresponsive to the needs of society) so that industry could not accept the curriculum materials used in the learning process. Entering the era of rising, MA's vocational curriculum is using a School-Based Curriculum (SBC) that is composed according to:

$>\quad$ potential and interests of learners

$>\quad$ diversity of learners' characteristics, local conditions, with no discrimination against religion ethnicity - culture - customs - socio-economic - status - gender 
$>\quad$ in line with the development of science, technology and art

$>\quad$ relevance to education and the needs of industrial societies

$>$ methods which are comprehensive and sustainable

$>\quad$ life-long learning

$>\quad$ balance between national and regional interests

Technically, the government requires implementing SBC for 38-42 hours per week. Nonetheless, based on the needs and peculiarities of the school, the principal and her leadership team have agreed to develop a learning curriculum of MA SMK 50 hours per week with additional local content: foreign languages (English, Mandarin-Chinese, French, Japanese), accounting (tested and certified), computers (tested and certified by an outside party), Galileo and Amadeus reservation tickets on line for the study program Travel-Tourism business (tested and certified by an outside party), E-Hors for reservation on line in study program Hospitality and Hotel Accommodation (tested and certified). The learning teaching activity (KBM), or so-called intra-curricular, starts at 06:30 a.m. and ends at 13:45 p.m., with a composition of 40\% theory and $60 \%$ practicum. To strengthen results, the learning process is supported by extra-curricular activities (learning beyond the curriculum intra) which are able to develop the interests and talents of students (the material is not contained in the intra-curricular). What Sr. Y shared during the interview was a further explanation to confirm the findings from the school document data.

Sr. Y said: .... Developing a school is not easy, and there are no short-cuts, and many things have to be considered such as curriculum design, need assessment of today's business and industries, and many others; anyway everything must be updated. (Y-3)

The learning process teaches students the values of honesty - discipline - responsibility - entrepreneurial spirit - care for environment. Putting these values into practice, the principal collaborates with a variety of parties competent in their field, namely:

$>\quad$ Character Team Building of Joseph Freinademetz foundation for intellectual and spiritual coach

$>\quad$ Surabaya University faculty of Psychology for training in leadership skills

$>\quad$ International Business management and Technology for entrepreneurship

$>\quad$ Pembangunan Institute for basic accounting

For increasing the ability and skills of teachers, the principal is networking with relevant agencies: National Surabaya University (UNESA), Association of Indonesian Hotels and Restaurants (PHRI), Tourism Association (ASITA) and Indonesian Fashion Designers Association (APMI).

For improving the skills course, each program of study has to perform the development of Production Unit (UP), such as UP Catering for serving food and beverage orders at weddings, thanksgiving prayer services, while the production of cakes and breads is supplied to Vincentius a Paulo Hospital and several other schools; UP Fashion Design is developed to create uniform students, to receive outside orders in the form of household linen, bags, slippers for hotel, and etc; UP Tourism Accommodation for developing a hotel room rental, cleaning service, security; UP Business Travel is developed to create a package tour for students and other agencies, book tickets. EP stated:

On the rising era: analyzing work opportunities in industries and society requires then we design additional curricula to support competency in fields like foreign languages, entrepreneurship, plus basic accounting, on-the-job-training, and oriental cuisine. (EP-2) 
Transforming a school: A case study of a Catholic school principal in Indonesia

$O$ and $D$ said: The most favorite departments at MA SMK are catering (culinary skills) and travel-tourism business because MA SMK has more practicum 3 times per week, whereas in public vocational schools practicum occurs only once a month. Also, MA SMK has collaboration with famous companies and industries. Our bakery products are well-known in Surabaya. Every year the number of students increases greatly. Our progress of learning: we continue to develop courses in four foreign languages, productivity and sharing skills and talents. (O-D-2)

\subsection{Student Organization}

The role of student affairs is to shape the character of students through coaching interests and talents developed in extra-curricular activities. Some extra-curricular activities offered by the school are:

$>$ Distributions of student talents: Artistic events (music band, choir), Sport activities (futsal, basketball).

> Supporting academic activities: academic activities (English, Japanese, Mandarin-Chinese, French, and tutoring), life skills (cake decoration, fashion design, Youth Red Cross/PMR).

To improve the effectiveness of coaching, the principal built a team called K-3 (Discipline-Neatness-Orderliness). The main task of K-3 team was to supervise and take action against student violations rule of regulations agreed upon by students, parents and the school. As a Catholic School, MA SMK has a Catholicity Team with the role to support spiritual activities with Christian values through participation at Mass, celebration of religions holidays, social service, mental coaching/mental building for psychological and spiritual strengthening, recollections, and retreats. Other development activities in the area of student affairs include race competition, student work performance, and exhibition expertise. Two students $(\mathrm{O}$ and $\mathrm{D})$ stated:

Two of our school regulations are discipline and punctuality, so students have to make psychological efforts. Moreover, MA SMK provides basic exercise for leadership, psychological and spiritual faith formation for the integral growth of students (e.g. rehearsals for spiritually-related events, military training and live-ins). (O-D-3)

\subsection{Public Relations}

Public relations activities inform local society through networking and collaborating with related institutions of various school events. A few of the institutions are the Department of Education, Local Industries, Parents, Junior High Schools, and relevant social organizations. The Marketing Team conducts networking with Junior High Schools to spread news of MA SMK outside Surabaya (East Java Island), even to Kalimantan Island, Bali Island, Sumatra Island, Sulawesi Island, and nearly all the islands of Indonesia. Moreover, to make the name of MA SMK more known from 2011 till now, MA SMK has collaborated in service learning with Fu Jen Catholic University and Shu Guang Catholic High School in Taiwan. To accommodate students who want to find a job in industry, MA has a Job Market Team which gives information about the employment opportunities and conditions in various workplaces in industry. To sharpen student skills, the school cooperates with local and foreign institutions.

\subsection{Infrastructure}

In the dying era, in certain respects the physical plant was so poor that students were uncomfortable in the learning process. The facilities for teaching-learning were still dependent on conventional equipment for practicum, so results were unable to reach the industry standards. In the rising era, the principal provided new buildings and equipment needed for study in both inside and outside the school. First of all, the principal renovated classrooms for theory and practicum, also procured industry standard equipment for expert practice, and cultivated school-based settings for a green environment, with shaded gardens that impacted on increased public interest. To accommodate the increasing number of new students, at the present time, the principal plans 
to build larger classrooms. Moreover, the principal is providing additional facilities such as installation of CCTV, air conditioners, and free Wi-Fi networks that are more attractive to the general public. W's comments:

Our principal has made a big change in our administrative office by establishing our centralized computer system. All classes have LCD. (W-2)

In the year 2012, the principal renovated a new building comprising 7 classrooms in excellent condition (the quality is above Indonesian vocational school standards), and also created a waste water treatment plant by the name of Zero Waste Water System (ZWWS), for which last year (2012) the school received the first award on the National level for "a caring school environment" (Adiwiyata).

W's comments: The school atmosphere gradually changed a lot with the Adiwiyata program (environmental education). As a result, we have our waste water treatment plant (ZWWS), and biopolymer well, as well as a greenhouse which uses coconut fiber instead of soil. (W-3)

Moreover, E has confirmed what the principal has done for the improvement of the MA vocational school.

She said: Principal $Y$ gives skill-training, full trust, authority and freedom to all the heads of programs to develop and innovate by using our creativity. She advises us to learn "the groove" of MA first and to be "on the spot". She wants us to share programs (if we have new programs, be willing to share), and at evaluation time she asks us to make "on the spot" analysis. ....she wants honesty and responsibility, nurtured in team coaching in programs (live-ins and retreats) and written in coaching reports. For entrepreneurship, we collaborate with IBMT by participating in competitions. All teachers, according to ruler in "human resources" must have, as a minimal, a Bachelor's degree, as well as appropriate special training. For advanced study, the school pays 50\% of the tuition, and the teacher 50\%. To improve students' skills, she provides on-the-job-training (catering, bakery, travel-tourism, garment business, hotel hospitality)....... Our management team (principal, four vice principals, four heads of departments) designs programs, holds annual evaluation for internal audits, twice a year evaluates for external audits. Our cooperation with her is top-down and down-top, gives opportunities to straighten out problems by mutual control. We need time, energy, hard work, and thoughts for synergy from top management. Outside the team, we find difficulties in coordination, so we need to support each other. As long as we have commitment and consistency with the programs, we can overcome the barriers of time and energy. (E-4)

M's comment: .... Networking with industries and factories continues, so our students are recognized more than undergraduate students. Students from other islands know MA through our website. Improving our vocational school, our principal gives a clear direction about the work world for students. Her motherly approach to students makes them feel at home, and the school becomes their second home. The most important key to transform MA into a qualified school is the principal's strategies, which effectively lead the school community to reach high performance... in 2006 MA reached a milestone by enhancing its curriculum with four foreign languages, and programs in hotel hospitality, and tour-travel. We had the courage to place students in outer islands so now MA is more well-known... Cooperation with our principal is important, but so is mutual concern, support for promotion, and compatibility in exchanging ideas. She is supportive, and shows loving care for the needs of our school community. (M-4)

Y's comment: ..... I use participative leadership strategies. I involve all teachers, staff and parents of students in accordance with their respective roles. I think the transformation was the result of participative leadership. In the past, this school was so passive, apathetic and almost hopeless. I was so challenged to see this school as my field service. Only when armed with a spirit of devotion to God, I was willing and ready to help lift MA SMK up. (Y-4) 
Transforming a school: A case study of a Catholic school principal in Indonesia

V's comment: Our principal developed many areas at MA, such as physical plant, teaching-learning process, green environment, HR, media learning - technology literacy, operation of LCD, laptop, power-point, and so on. She cared about our special facilities (computer lab, language lab), our student center, financial management system, and our vision-mission statement as a direction to form our mind-set to focus on nurturing love, SSpS spirituality, and "committed to life" through retreats for teachers, staff and students. In meetings she always reminds us about the values that animate our vision. In my observation, 90\% of our vision and our mission-values are now implemented in the hearts of teachers and staff, so we have a sense of belonging to the school and our students. She also asks us to embrace all students and show no discrimination because our duty as teachers is to transform all students into capable students in work. If something goes wrong, she easily gets angry by challenging us and yet encourages us through her loving care. She motivates students to be proud of themselves, because although still young, some are yet already able to earn money and work skillfully, whereas high school students at the same age may not yet have a job....... (V-5)

\subsection{Collaboration and Communication}

Literature has shown that clear communication can foster more effective collaboration. By clearly communicating their expectations and reaching out for wider collaboration, principals can enlarge holistic partnerships or interconnections with other schools to improve their own schools. For example, teamwork among teachers, linkup among schools and business companies for financial support and partnerships among schools and other public agencies to team up in social services for all of us (Johnson, 2000).

Y's comment: To transform this school, first of all, I used participative leadership because I needed all the MA community to participate in synergy. A Principal should be in collaboration with the Vice Principal matters (Curriculum, Student, Public Relations, Marketing, on-the-Job-training), government (Ministry of Education on the city and province level). Moreover a principal is also working with the Heads of Departments/programs: the Catering Program, Program in Hospitality Accommodations, Service Business Travel-Tourism Program and Fashion Design Program. (Y-5)

EP stated: .... The strategies of our principal that I appreciate most are first she built solid teamwork, then renovated our physical plant, and collaborated with those who open widely opportunities to improve. She has called for regular meetings for sharing and discussion, and encouraged others by giving inspirational talks. For example, she said, "If our school is dead, we're also dead! So we should dare enough to compete, yet we need the "plus values" that are different from other schools. Together we can do it; definitely we can harvest good fruits. Be optimistic and, above all, you have to rely on God through prayers and good deeds!" (EP-4)

At MA SMK, to foster effective communication, the principal (Sr. Y) utilizes public relations to inform local society about the school and to promote it through networking and collaborating with related institutions namely, the Department of Education, local industry, parents, junior high schools, and the general public.

The research of Rosenholtz (1989) on teacher work environment emphasized the essential necessity for collaboration for teacher competence and student performance. From research data, Rosenholtz classified that schools which grow were identified by concurrence on purposes, mutual help and the sharing of teachers, participation in decision making related to work, and chances to promote self-learning.

Y's comment: ..... We always have a routine meeting to coordinate every time when there is a change or a new program. Sharing, confirmation and clarification are always open for the progress of school. We also accommodate and respond to each person's aspirations. (Y-6) 
Most teachers in schools that develop and influence society vocalized a hopeful and positive view of themselves and their capacity - that "everything was possible" (Rosenholtz, p. 210). The results of the Rosenholtz's study also boosted the hypothesis that there were more advantages than disadvantages to collaboration for professionals as well as for students (p. 210). A quotation from a teacher (E) explains further:

For entrepreneurship, we collaborated with IBMT by participating competitions. Care for the environment was routinely integrated with the study of natural science and physics. She also unceasingly promoted MA through marketing to the whole of Indonesia with the use of networking system, an open house project, and participation in competitions and contests, so by expanding relations, more partners were recruited (universities, industries, junior-senior high schools social institutions). ..... To improve students' skills, she has provided on-the-job-training (catering, bakery, travel-tour guide, garment business, hotel hospitality). (E-5)

\subsection{Design Curriculum-Instruction-Assessment beyond Standards}

The curriculum is set up and manages the whole process of learning in the school, and demands a change in attitudes, knowledge and skills. According to teacher (E), doing the assessment and instruction periods, first of all, the school principal offered advice:

She advised us to learn the groove of MA first and we should be "on the spot". We should share programs (if we have new programs, be willing to share), and in evaluations, she asked us to make "spot analysis". (E-6)

The findings from document data analysis of MA SMK reveal that in the dying era, MA SMK implemented vocational curriculum purely from government policies (had not yet developed a curriculum that was interesting and in response to the needs of the society) so that industry could not accept curriculum materials used in the learning process.

Entering the era of rising, MA's vocational curriculum is using School-Based Curriculum (SBC) that is composed according to: 1) potential and interests of learners; 2) diversity of learners' characteristics, local conditions, no discrimination against religion - ethnicity - culture - customs - socio-economic - status - gender; 3) following the development of science, technology and art; 4) relevance to education and the needs of industrial societies; 5) comprehensive and sustainable; 6) life-long learning; 7) balance between national interests and regional interests.

Y's comment: ..... Developing a school is not easy and has no short-cut, many things have to be considered such as curriculum design, need assessment of today's business and industries, etc; anyway all have to be updated. (Y-3)

Technically, the government requires implementing SBC in 38-42 hours per week. Nonetheless based on the needs and peculiarities of the school, the principal and her leadership team make an agreement to develop a learning curriculum of MA SMK 50 hours per week with additional local content: foreign languages (English, Mandarin-Chinese, French, Japanese), accounting (tested and certified), computers (tested and certified by an outside party), Galileo and Amadeus reservation tickets on line for the study program Travel-Tourism business (tested and certified by an outside party), E-Hors for reservation on line in study program Hospitality and Hotel Accommodation (tested and certified). Further explanation was given by teachers.

M said: And in 2006 it reached the peak by enhancing curriculum with 4 foreign languages, hotel hospitality, tour and travel ... (M-5)

EP stated: ....... Our rising era: analyzing work opportunities in industries and society requires then we design additional curriculums to support competency such as foreign languages \& entrepreneurship plus basic accounting, on-the-job-training, oriental cuisine. Because of having 
Transforming a school: A case study of a Catholic school principal in Indonesia

courage to innovate, the government supports and gives us authority to develop our own curriculums. (EP-5)

Learning teaching activity (KBM) or so-called intra-curricular starts at 06.30 a.m. and ends at 13.45 p.m., with a composition of $40 \%$ theory and $60 \%$ practicum. To strengthen the achieving result, the learning process is supported by extra-curricular activities (learning beyond the curriculum intra) which are able to develop the interests and talents of students (the material is not contained in the intra-curricular). Two students stated:

The most favorite department at MA SMK are catering (culinary skills) and travel-tourism business because MA SMK has more practicum 3 times per week whereas in public vocational schools their practicum has only once a month; and also MA SMK has channels in collaboration with famous companies and industries. Our bakery products are well-known in Surabaya. Every year the number of students increases drastically. Our progress of learning: 4 foreign languages, productive and sharing skills and talents. (O-D-2)

The learning process teaches students the values of honesty - discipline - responsibility - entrepreneurial spirit - care for environment. Putting these values into practice, the principal collaborates with a variety of parties competent in their field, namely:

$>\quad$ Character Team Building of Joseph Freinademetz foundation for intellectual and spiritual coach

$>\quad$ Surabaya University faculty of Psychology for training in leadership skills

$>\quad$ International Business management and Technology for entrepreneurship

$>\quad$ Pembangunan Institute for basic accounting

For increasing the ability and skills of teachers, the principal is networking with relevant agencies: National Surabaya University (UNESA), Association of Indonesian Hotels and Restaurants (PHRI), Tourism Association (ASITA) and Indonesian Fashion Designers Association (APMI).

For improving the skills course, each program of study has to perform the development of Production Unit (UP) such as UP Catering is developed for serving food and beverage orders of weddings, thanksgiving prayer, while the production of cakes - breads is supplied to Vincentius a Paulo Hospital and several other schools; UP Fashion Design is developed to create uniform students, to receive an order from the outside in the form of household linen, bags, slippers for hotel etc; UP Tourism Accommodation be developing a hotel room rental, cleaning service, security; UP Business Travel is developed to create a package tour for students and other agencies, book tickets.

\subsection{Developing of Learning and Teaching}

According to the findings of school document, learning teaching activity is supported by extra-curricular activities (learning beyond the curriculum intra) which are able to develop the interests and talents of students (the material is not contained in the intra-curricular).

V stated: .....Our principal develops many areas of MA such as teaching-learning process...media learning - technology literacy how to operate LCD, laptop, power-point, etc.... $(\mathrm{V}-5 \mathrm{a})$

The values to be achieved in the learning process are to become a student of honesty - discipline responsibility - entrepreneurial spirit - care for environment. In this case, a teacher $(\mathrm{E})$ stated:

Honesty-responsibility will be trained by team coaching in programs (live-in, retreat) and written in coaching report book. (E-7) 
For increasing the ability and the skills of the teachers, the principal is networking with the relevant agencies: UNESA, PHRI, ASITA, and APMI.

V shared: What I appreciate most is she gives us a chance to study further and delegates us to attend important meetings so we can learn more knowledge and leadership. She told us, "This school is your fixed income for feeding your families. If the school is shut down who will suffer?! The future of this school is in your hands to carry on! I'm not here forever, so you must learn unceasingly to gain more knowledge and skills how to improve your school." (V-6)

For improving the skills course, each program of study has to perform the development of Production Unit (UP) such as UP Catering is developed for serving food and beverage orders of weddings, thanksgiving prayer, while the production of cakes - breads is supplied to Vincentius a Paulo Hospital and several other schools; UP Fashion Design is developed to create uniform students, to receive an order from the outside in the form of household linen, bags, slippers for hotel etc; UP Tourism Accommodation be developing a hotel room rental, cleaning service, security; UP Business Travel is developed to create a package tour for students and other agencies, book tickets. As proved by the students and alumna statements:

Our bakery products are well-known in Surabaya...... Our progress of learning: 4 foreign languages, productive and sharing skills and talents. (O-D-5)

What I have learnt as an hotelier in MA SMK is we are educated holistically in hospitality by paying attention to the detail of our loving service. Meaning to say we are doing all round in cleaning service even expertise in sensing many kinds of chemical liquids and polishing shoes. These trainings are very helpful when I am further studying in University. I'm proud of MA because the school always makes efforts to develop, to improve and update constantly, not only maintaining but also increasing the quality and facilities, attention to detail and we were given a lot of skills provision. (T-2)

\subsection{Fostering Professional Development}

Based on several research studies of Hawley and Valli (2000), one of the integrating principles for designing effective "learner-centered" professional development was "continuous and ongoing, engaging follow-up, support for further learning and from sources external to the school that can provide necessary resources and outside perspectives" (pp. 1-6). This statement is in line with the findings of school document which are written that human resource is the most important component in a work plan, in implementing, evaluating and analyzing the work program to reach out a target with maximal results. So towards the end of the school year there is always an assessment of the performance of teachers and employees and a recommendation for continually increasing the quality of education. To develop the human resources, the school principal provides seminars-workshops, educational training, work practices, comparative studies and advanced studies. Some quotations from participants give further confirmations.

E said: $Y$ principal gives skill-training, full trust, authority and freedom to all the heads of program to develop \& innovate by using our creativity. She advises us to learn the groove of MA first and to be on the spot; shares programs (if we have new programs, be willing to share); on evaluation time she will ask us to make spot analysis. (E-8)

V stated: ..... What I appreciate most is she gives us a chance to study further and delegates us to attend important meetings so we can learn more knowledge and leadership. Y told us, "This school is your fixed income for feeding your families. If the school is shut down who will suffer?! The future of this school is in your hands to carry on! I'm not here forever, so you must learn unceasingly to gain more knowledge \& skills how to improve your school." (V-6) .... motivating students to be proud of themselves who are still young yet already able to earn money and work 
Transforming a school: A case study of a Catholic school principal in Indonesia

skillfully whereas high school students have same age but not yet have a job;...... (V-7)

Ra said: ....... Sr. Y principal encourages my daughter to study further and gives her a chance to participate in a contest. Thanks be to God, she got the third prize. Then after graduation, she works in the administration office of MA. (Ra-2)

\subsection{Supportive Learning Condition}

Holtz Frank (2006) defined a supportive learning condition as "the creation of a caring, rigorous and relevant learning community that provides support to all learners in aiding them to achieve at their highest potential" (pp. 1-2). In brief, Shannon and Bylsma (2007) gave expression that "mutual respect and trust are at the heart of a supportive learning environment" (p. 107). To sum up the understanding of a supportive learning condition, the researcher considers that the key to a supportive learning environment is the willingness of the whole school community to respond to the call of loving care for humanity to build a caring relationship with all students, learn about their needs and strengths, and provide support and encouragement the students' desires to be successful learners.

E said: ..... Environment care is routinely integrated in learning natural science and physics.......The school building was also renovated, provided modern lab facilities for study. (E-9)

EP stated: ......then renovates our school physical buildings... (EP-6)

W's comments: ..... The school atmosphere gradually changed a lot with Adiwiyata program (environmental education). As a result, we have waste water treatment plant (ZWWS), biopolymer well, built up a greenhouse by using coconut fiber instead of soil. There we plant medicinal plants (abbreviated TOGA) which is a plant cultivated as a nutritious home-based medicine, also other plants such as orchid, rose, greenery plants, etc. Anyway, our school becomes a sustainable school which is covered in greenery, beautiful garden, fresh \& fragrant green environment. (W-1-3-5)

O and D's comments: ....... We are proud of our school because we have beautiful, comfortable and healthy environment with garden-waterfall view. So we also need effort to protecting our environment by doing inorganic \& organic waste recycling, bring a plant then planting it in our school garden. (O-D-6)

\subsection{Family and Community Involvement}

The findings of thorough analysis of school document data and participants' interviews reveal that the wider community means the Department of Education, Industry world, Universities and Junior High School. Department of Education serves as a protective institution, development of educational resources, sources of funding, coaching and assessment. Industry world is the major goal of graduating students to work according to their expertise, but also it is a place to practice skills for students and teachers as well as resources to the development of tourism industry. Besides that, the school establishes good relationships with some of families were able to be benefactors for students who have financial problem for paying their study. On the other hand, Epstein (2008) notes that successful students at all ability levels have families who keep contact to the school principal and teachers just asking for information and involve in their children's education. To further exemplify, an alumna (T) stated:

I really experienced her motherly love. I'm a handicapped student but she accepted me wholeheartedly. She allowed me to stay in the dorm. She encouraged and empowered me to be myself who could do my best as normal students do. Even though I already graduated, I still keep in touch with her, just for sharing or asking her advice. (T-3) 
Y's comment: ..... I believe in them, respect and ensure their welfare. For example: Earnings Canteen and production unit are divided into three: for operational, for poor students and for the welfare of teachers. (Y-7)

Ra stated: ...... I am from a poor family so my daughter got financial support from the principal ......... (Ra-3)

V said: ...... If the work team is well done, she gives rewards by going outing and eating together with all teachers, staff and even the cleaning-service workers. She is pretty much care to the school community's families. She approaches them in person, those who are sick, she will visit them. Her loving care gives us example of affection. For our welfare, we have a compulsory credit union which we have to deposit Rp. 5000/ month for unexpected use (sickness, death, etc).... establish relationships \& cooperation with parents who are our sponsors by giving them insights through parents-teachers meeting because they have a role to develop our school; giving division of responsibilities, establish partnership with business industries \& school institutions, maintaining, those who are in-the-job-training doing a good job will directly be hired in that work place..... (V-8)

\subsection{Shaping School Culture}

The key finding on shaping school culture is not included in the nine characteristics of high-performance school based on the research of Shannon and Bylsma (2007). But through the interview analysis, the researcher finds out that 12 participants consider shaping school culture as a significant theme which the school principal used as one of her strategies to transform MA SMK into a high-performance school. For shaping school culture, the school principal (Y) prioritizes five values (discipline - honesty - responsibility - entrepreneurship environment care) that operationally are done by K3 team to monitor students' discipline. Through direct observation, the researcher assumes the culture of school is embedded in a caring and nurturing environment. To implement the value of school culture in the hearts of all persons in school community, the principal engraves a motto of MA at the top of the main gate and at the wall of school along the corridor "Excellence in Quality, Courtesy in Action" is a way of life to reach the GATE OF SUCCESS. With motherly approach in welcoming the students at the main gate, the school principal empowers, encourages and motivates school community "you can!" Her motherly love makes the students feel at home and the school becomes their second home.

Vn said: ...... The school culture is being updated especially enforcing green environment, discipline, openness and freedom in creativity, heterogeneous friendship. (Vn-3)

T stated: ...... I'm so grateful for study in MA SMK which has strict discipline school culture but be able to transform the students into persons of faith who are not only sharpened the brain but also the heart as persons of integrity. (T-4)

M said: ..... School culture improved because vision-mission SSpS implemented in MA and the key value is DICIUM and KISS; so parents entrusted their children to study in MA. ..........Her motherly approach to the students makes the students feel at home and the school becomes their second home. (M-6)

\subsection{Using SWOT Analysis}

Another strategy that does not belong to the nine characteristics of high-performance school based on the research of Shannon and Bylsma (2007) is SWOT analysis. From the interviews of 12 participants, 10 participants consider SWOT analysis as one of the most significant strategies the school principal used for transforming MA SMK into a high-performance school because since Sr. Y is a new school principal at MA SMK, she starts using SWOT analysis in doing evaluation for all aspects of the school. 
Transforming a school: A case study of a Catholic school principal in Indonesia

10 participants have similarity in answering this strategy: ...... Her strategies to transform MA into a qualified school are: using SWOT analysis to improve our teaching-learning methods/ programs curriculums, school culture, environment, self-evaluation; marketing how to market your skills - products, collaboration in marketing and education...... Our rising era: using SWOT analysis, we start analyzing work opportunities in industries and society needs then we design additional curriculums to support competency such as foreign languages and entrepreneurship plus basic accounting, on-the-job-training, oriental cuisine ... (E-M-V-W-O-D-EP-Y-X-Vn)

\subsection{Product Marketing}

MA SMK is a vocational school which prepares graduates to become skilled workers ready for use. So if the students' hand-made productions are qualified and sold well, automatically the students and their hand-made productions get more opportunities to compete in many contest events as means of promotion for being increasingly known to the public. For this reason, the 12 participants consider product marketing strategy as the most essential issue because it gives students 'a room' to develop their skills and talents. Product marketing is not found in the nine characteristics of high-performance school based on the research of Shannon and Bylsma (2007).

X's comment: the most important strategy of the school principal in transforming MA SMK into a qualified school is through product marketing at the same time promoting the school to all levels [all islands in Indonesia, school institutions (Junior High Schools, Universities), industries, companies, etc]; updating the new system; optimistically move forward; and make clear reports. $(\mathrm{X}-2 \mathrm{a})$

E explained: ....... For entrepreneurship, we collaborate with IBMT by participating competitions. ....... Join competitions/contest so by expanding relations the more partners recruited (universities, industries, social institutions, junior-senior high school). Students and their hand-made productions get more opportunities to compete in many contest events as means of promotion for being increasingly known to the public. (E-11)

M stated: .......selling, promoting and marketing the product of students' work, networking with industries, factories so the students are recognized more than undergraduate students. (M-7)

\subsection{School Promotion}

From the interviews analysis, the study indicates that school promotion is the most significant strategy for 12 participants. But unfortunately, school promotion strategy is not mentioned in the nine characteristics of high-performance school based on the research of Shannon and Bylsma (2007). According to four teachers, board of trustee and the school principal participants, after renovating the physical plant of MA SMK and providing high standard infrastructure facilities, the school principal enthusiastically makes a vigorous effort promoting the school to the entire Indonesia.

M's comment: ....... In 2004/2005 the first year of school marketing promotion we got 125 students then increased till 159 students. After that each year getting constantly increase. (M-8)

E stated: ..... She also unceasingly promotes MA through marketing to the whole Indonesia, networking system, open- house, and join competitions/contest so by expanding relations the more partners recruited (universities, industries, social institutions, junior-senior high school). Students get more opportunities to compete in many contest events as means of promotion for being increasingly known to the public. (E-12) 


\section{The Impact of These Strategies on the School Community}

When asked 'did the school principal's strategies make a great impact on the school community?' the participants answered, "Yes, indeed." Then the researcher continued asking "why do you consider the impact great?" and "which strategies have Sr. Y used that give the biggest impact in developing MA SMK?" Most of the answers were as follows:

A. Through school promotion, the number of students constantly increased and the school is chosen as the most outstanding school IBMT version.

B. Through expecting all students achieve high standard, our school possessed high performance with a lot of awards.

C. Through shaping school culture, the students feel at home and the school becomes their second home; moreover, the students transform into persons of faith who are not only sharpened the brain but also the heart as persons of integrity our school is trusted by parents and donators.

D. Through products marketing, our bakery products become well-known in society, the salary of teachers and staff increases.

E. Through professional development, we are able to increase student achievement and high quality of teaching-learning process through skillful teachers who get the opportunity to advanced study.

F. Through a clear and shared Vision-Mission-Goal-Direction, we increase our sense of belonging towards school.

G. Through supportive learning condition, our school has high standard infrastructure facilities and got the first prize as a caring environment school in national level.

\section{The Perceptions of School Community towards the School Principal}

The school community perceives these school principal strategies as a big challenge yet a successful action. Through the key words of the interviews analysis, the researcher finds that because of the powerful role of the school principal so these strategies are able to be implemented successfully. The participants' perceptions towards the school principal refer to the powerful role of the principal as

A. A motivator which 11 participants mention (encouraging the teachers and students "Be a professional and updating teacher not just by the book", "be a ready-made skillful work students", giving direction, challenging).

B. A visionary perceived by 10 participants (dare to dream high, constant updating, widen horizon, open-minded in accepting other's opinions, have sharp eyes and heart of marketing/entrepreneurship).

C. Moral agent which 12 participants mention (acceptance others' mistakes and also hers; be on the spot or be there/present here and now; she is strict, strong discipline; whatever we do or say should give a reason; no favoritism, hardworking, perseverance).

D. A charismatic leader and organizer which 12 participants mention (Optimist, convince others by giving examples and witness/ leading by example, energetic, teaching from her heart, putting the right person to the right place, smart to look for a breakthrough in finding job channels for students, a skill in listening, good in decision-making and calculating, have courage to start something new with self-confidence, to make a difference and to compete, down-to-earth person, touch the heart of the people, a big heart, an integrated person, supportive, loving care to the needs of school community, willingness and readiness to learn something new, have golden hands, a woman of wisdom and deep 
faith).

E. An empowerer to whet their talents perceived by 12 participants (delegating, transformation, fostering, educating, giving space to grow, to be creative, and generosity).

F. A team builder perceived by 10 participants (family approach, ask for reaching an effective synergy, build solid teamwork).

G. A communicator which 12 participants mention (have a capacity to relate with others as brothers and sisters/make friends with a lot of people/be a friend for students, scolding others with her sense of humor).

While clustering the key findings of the perceptions of the school community towards the school principal and crossing check data triangulation of the answers participants given from interview questions on what kind of person Sr. Y as a principal is and the reason why they consider Sr. Y is a good principal, the researcher discovers the profile of the school principal. Based on the in-depth interviews data analysis, the profile of the school principal is she has a welcoming attitude which is revealed by teachers, students, administrator, board of trustee and parents who say that she is hearty welcome to the poor and with her friendliness, she creates kinship with the school community in family atmosphere, generously makes friends with others, respects them and keeps good personal relationship with every one without favoritism. Because of her fairness, honesty, reliability, accountability and openness, people trust what she says is what she does (her doing-being is integrated). Specifically, the board of trustees, parents, and the school principal herself stressed the most important thing was the benefactors trusted her that is she has a spirit of enough which means she is not asking the amount of money more than the school needs.

Besides that, her persuasive-supportive attitude and her risk-taking by trial-error give others authority, freedom and a space to grow and develop their talents and potentials. Although she easily gets angry when something goes wrong, even challenging, yet she encourages them with loving care. Motivating, caring, encouraging, empowering, and acceptance are her educational values that rekindle and vitalize the school community. On top of that, what the school community admire at her are: she is educating in head and heart as well, optimist, frankly speaking, to the point, no mince words, responsibility in doing her task, reasonable, giving clear reports, realistic (true-to-life). With pride, they call her a woman of wisdom and deep faith, a charismatic and visionary principal.

\subsection{Summary}

\section{Table 1}

Summary of Chapter IV on Findings and Discussion

\begin{tabular}{ll}
\hline \multicolumn{1}{c}{ Research Questions } & \multicolumn{1}{c}{ Key Findings } \\
\hline The Strategies & Setting a clear and shared focus (Vision-Mission-Goal-Direction = VMGD) (11) \\
& Expecting all students to achieve high standards (12) \\
& Effective Leadership-Management (11) \\
& Collaboration and Communication (11) \\
& Design Curriculum-Instruction-Assessment beyond Standards (10) \\
& Developing of Learning and Teaching (10) \\
& Fostering Professional Development (12) \\
& Supportive Learning Condition/Environment (12) \\
& Family and Community Involvement (12) \\
& Shaping School Culture (12) \\
& Using SWOT Analysis (10) \\
& Products Marketing (12) \\
& School Promotion (12) \\
&
\end{tabular}


Table 1 ... continued

\begin{tabular}{lll} 
Research Questions & \multicolumn{5}{c}{ Key Findings } \\
The Impact & (Expecting all students to achieve high standard, product marketing, school
\end{tabular}
promotion, professional development, shaping school culture, supportive learning environment, VMGD) => Increase: Students' achievement - the number of students the salary of teachers and staff - sense of belonging; become well-known school, trusted by parents and donators.

The Perception The school community perceive the strategies as a powerful role of the principal: A motivator (11) (encouraging the teachers and students "Be a professional and updating teacher not just by the book", "be a ready-made skillful work students", giving direction, challenging)

A visionary (11) (constant updating, widen horizon, open-minded in accepting other's opinions, have sharp eyes and heart of marketing/entrepreneurship)

Moral agent (12) (acceptance others' mistakes and also hers; be on the spot or be there/present here and now; she is strict, strong discipline; whatever we do or say should give a reason; no favoritism, hardworking, perseverance)

A charismatic leader and organizer (12) (Optimist, convince others by giving examples and witness/ leading by example, energetic, teaching from her heart, putting the right person to the right place, smart to look for a breakthrough in finding job channels for students, a skill in listening, good in decision-making and calculating, have courage to start something new with self-confidence, to make a difference and to compete, down-to-earth person, touch the heart of the people, a big heart, an integrated person, supportive, loving care to the needs of school community, willingness and readiness to learn something new, a woman of wisdom and deep faith)

Empowerer to whet their talents (12) (transformation, delegating, fostering, educating, giving space to grow, to be creative, generosity)

A team builder (10) (family approach, ask for reaching an effective synergy, build solid teamwork)

A communicator (12) (have a capacity to relate with others as brothers and sisters/make friends with a lot of people/be a friend for students, scolding others with her sense of humor)

\section{Conclusions}

After collecting the key findings and discussing them in the lens of literature review - direct observation deep analysis of the interviews and document data, the researcher takes some time to reflect on them and gains some surprising insights and unexpected results through conducting this phenomenological case study. This study is dynamic because a phenomenological research is focused on lived experiences. Focus on and learn from a school principal in Surabaya Mater Amabilis Vocational School (MA SMK), the main objectives of this case study are to investigate (1) the strategies used by the school principal in transforming MA SMK into a high-performing school, (2) the impact of these strategies on the school community (students, teachers, parents, alumna, Board of Trustee, and administrator) and (3) the perceptions of the school community towards the school principal. The achieved findings are presented as follows:

First, this current study has shown that from thirteen strategies the school principal (Sr. Y) used, nine of them are positively relevant to the previous study of Shannon and Bylsma (2007)'s nine characteristics of high-performing schools: (1) clear and shared focus (Vision-Mission-Goal-Direction), (2) expecting all students to achieve high standards, (3) effective leadership-management, (4) collaboration and communication, (5) curriculum, instruction and assessment beyond standards, (6) developing of learning and teaching, (7) fostering professional development, (8) supportive learning condition/environment, (9) family and community involvement. While, the other four strategies are specifically used by the school principal in transforming MA SMK into high-performance school: (10) shaping school culture, (11) using SWOT analysis, (12) product marketing and (13) school promotion. These specific four strategies are uniquely found at MA SMK. The researcher predicts the possibility is because this study focused on a phenomenon vocational school principal 
conducting her strategies whereas prior studies are in high schools.

Secondly, as for the impact of these strategies on the school community (students, teachers, parents, alumna, board of trustee, and administrator); the results of interviews with 12 participants have shown that there are seven strategies which significantly give big impact on the school community, whereas, the biggest impact is either school promotion or product marketing. Lastly, as the school community gets impact from these strategies, so the perceptions of the school community towards them are associated with the school principal's role. By clustering and coding participants' interviews, the researcher finds seven given names, namely: a motivator, a visionary, moral agent, a charismatic leader and organizer, empowerer to whet their talents, a team builder, and a communicator. Although they consider Sr. Y is strict, strong discipline and easily gets angry when something goes wrong, yet still the school community praises her as their heroine for the growth of school and their very persons.

Based on the findings of this phenomenological case study and particularly the statements of the participants who have experienced with the school principal, the researcher acknowledges that the school principal (Sr. Y) is a wise down-to-earth principal who perceives students as a grace, gifts from God. She treasures and cherishes students as the pearls of future generation which need to be 'shining' by cultivating-training-nurturing-fostering their personal growth, achievements and motivations. As an educator, the school principal gives her loving care not only to students but all members of the school community, such as teachers, administration staff, parents, board of trustees, even the cleaning-service workers as well. Above all, the school principal has a charisma to lead, to organize and to manage the school and the people. So, indeed, the school principal positively gives a strong impact on the school community and her strategies are appropriate for MA SMK. She has 'a golden hand' to turn around and rise up the dying school into high-performing school.

\section{References}

Bottoms, G., \& Schmidt-Davis, J. (2010). The three essentials: Improving schools requires district vision, district and state support and principal leadership. Retrieved from http://www.sreb.org

Creswell, J. W. (2007). Qualitative inquiry and research design: Choosing among five approaches. Thousand Oaks, California: Sage.

DeVault, G. (2011). Establishing trustworthiness in qualitative research: What are qualitative research processes? Retrieved from http://marketresearch.about.com/Establishing-Trustworthiness-In-Qualitative-Research.htm

Epstein, J. L. (2008). Improving family and community involvement in secondary schools. The Education Digest, 73(6), 9-12.

Guion, L. A., Diehl, D. C., \& McDonald, D. (2011). Triangulation: Establishing the validity of qualitative studies. Retrieved from http://edis.ifas.ufl.edu

Hawley, W. D., \& Valli, L. (2000) Learner-centered professional development. Retrieved from http://www.pdkintl.org/research/rbulletins/resbul27.htm

Holtz Frank, T. (2006). Enhancing supportive learning environment ND student achievement through project ALERT. Retrieved from http://daretodifferentiate.wikispaces.com/file/view/319_EnhancingSLE_and_SA.pdf

Hycner, R. H. (1985). Some guidelines for the phenomenological analysis of interview data. Human Studies, 8(3), 279-303. http://dx.doi.org/10.1007/BF00142995

Izumi, L. T., \& Yan, X. C. (2005). Free to learn: Lessons from model charter schools. San Francisco: Pacific Research Institute.

Johnson, B. L. (2000). Organizing for collaboration: A reconsideration of some basic organizing principles. In D. G. Pounder (Ed.), Restructuring schools for collaboration (pp. 9-25). New York: State University of New York Press.

Lezotte, L., \& McKee, K. (2006). Stepping up: Leading the charge to improve our schools. Okemos, MI: Effective Schools Products, Ltd. 
Oei, S. F.

McLaughlin, M. W., \& Talbert, J. E. (2006). Building school-based teacher learning communities: Professional strategies to improve student achievement. New York: Teachers College Press.

Merriam, S. B. (1998). Qualitative research and case study applications in education. San Francisco, CA: Jossey-Bass Publishers.

Miles, M. B., \& Huberman, A. M. (1994). Qualitative data analysis (2nd ed.). Newbury Park, CA: Sage.

Miller, O. P. (2011). A phenomenological case study of a principal leadership: The influence of Mr. Clark's leadership on students, teachers and administrators at Eastside High School. (Doctoral dissertation, Georgia State University). Retrieved from http://scholarworks.gsu.edu/eps_diss/85

Patton, M. Q. (2002). Qualitative research and evaluation methods (3rd ed.). Thousand Oaks, CA: Sage.

Rosenholtz, S. J. (1989). Teachers' workplace: The social organization of schools. White Plains, NY: Longman, Inc.

Sergiovanni, T. J. (1995). The principalship: A reflective practice perspective (3rd ed.). Boston: Allyn and Bacon.

Shannon, G. S., \& Bylsma, P. (2007). The nine characteristics of high-performing schools: A research-based resource for schools and districts to assist with improving student learning (2nd ed.). Olympia, WA: OSPI.

Stephens, B. J. (2008). Comparisons between high-performing and low-performing charter schools. Retrieved from http://books.google.com/books?isbn=0549516662

Thurmond, V. (2001). The point of triangulation. Journal of Nursing Scholarship, 33(3), 254-256. http://dx.doi.org/10.1111/j.1547-5069.2001.00253.x

Yin, R. K. (2003). Case study research: Design and methods (3rd ed.). New York, NY: Sage Publications. 